\title{
Umbilical cord blood erythroblast count as an index of intrauterine hypoxia
}

\author{
B Thilaganathan, S Athanasiou, S Ozmen, S Creighton, N R Watson, K H Nicolaides
}

\begin{abstract}
The relation of umbilical cord blood arterial pH, Apgar score, leucocyte count, and erythroblast count at delivery with the diagnosis of fetal distress in labour was studied prospectively in three groups of singleton pregnancies delivering at term vaginally ( 55 infants), by elective caesarean section (39 infants), or by emergency caesarean section for abnormal intrapartum fetal heart rate patterns ( 55 infants). In the emergency caesarean section group the umbilical cord blood arterial pH was significantly lower and the leucocyte and erythroblast counts were higher than in the elective caesarean section group. Comparison of the emergency caesarean section and spontaneous vaginal delivery groups showed significant differences for $\mathrm{pH}$ and erythroblast count, but not for leucocyte count. In the spontaneous vaginal delivery group erythroblastosis was associated with umbilical cord blood pH, whereas leucocytosis was associated with the length of labour. The five minute Apgar score was $\geqslant 7$ in all infants. This study suggests that leucocytosis is a non-specific response of the fetus to labour, whereas erythroblastosis reflects fetal tissue hypoxia.

(Arch Dis Child 1994; 70: F192-F194)
\end{abstract}

Labour is associated with an increase in the number of erythroblasts and leucocytes in umbilical cord blood. ${ }^{12}$ Antenatal studies of pregnancies complicated by severe intrauterine growth retardation and red blood cell isoimmunisation have suggested that erythroblastosis may be the consequence of fetal tissue hypoxia. ${ }^{3-5}$ In contrast, the fetal leucocyte count in these disorders is decreased. ${ }^{67}$ The aim of this study is to investigate whether the erythroblastosis and leucocytosis associated with labour are the consequence of intrauterine fetal tissue hypoxia or a non-specific response to labour.
Patients and methods

Three groups of singleton pregnancies delivering at term were examined: (a) those delivered by elective caesarean section (39 infants) for reasons such as breech presentation, previous caesarean section, placenta previa, or unstable fetal lie; (b) those delivered by emergency caesarean section (55 infants) for presumed fetal distress because of abnormal intrapartum fetal heart rate patterns (baseline tachycardia or bradycardia and non-reactive decelerative pattern) with or without fetal scalp blood sampling; and (c) spontaneous vaginal deliveries after induced or spontaneous onset of labour. Data on the former two groups were collected over a three month period. Subsequently, data were collected from 55 consecutive spontaneous vaginal deliveries to examine the effect of labour on the measured variables.

At delivery the umbilical cord was double clamped and umbilical arterial blood was collected into heparinised syringes for the measurement of pH (Radiometer ABL 330, Copenhagen, Denmark). Cord blood was also collected into isotonic edetic acid solution and the total nucleated cell count was determined with a Coulter stacker automated cytometer (Coulter Electronics, Luton). Blood films were stained by the May-Grüwald-Giemsa method and the number of erythroblasts per 100 leucocytes was counted. The absolute erythroblast count $\left(\times 10^{9} / 1\right)$ was calculated.

\section{STATISTICAL ANALYSIS}

Mann-Whitney $U$ tests were used to determine the significance of any differences in data between the various groups of infants. In the spontaneous vaginal delivery group linear regression analysis was used to determine the significance of any associations between blood $\mathrm{pH}$, leucocyte count, and erythroblast count and the duration of labour. Multiple regression analysis was used to determine the contribution
The Harris Birthright Research Centre for

Fetal Medicine, King's

College School of

Medicine, London

B Thilaganathan

$S$ Athanasiou

$S$ Ozmen

$S$ Creighton

N R Watson

$\mathrm{K} \mathrm{H}$ Nicolaides

Correspondence to:

Dr Nicolaides.

Accepted 30 November 1993

Median (range) gestational age, birth weight, duration of labour, umbilical cord blood arterial pH, erythroblast count, and leucocyte count in the elective caesarean section (ELCS), spontaneous vaginal delivery (SVD), and emergency caesarean section (EMCS) groups. Significant differences between the groups are shown with the corresponding $p$ values

\begin{tabular}{|c|c|c|c|c|}
\hline & $\begin{array}{l}E L C S \\
(n=39)\end{array}$ & $\begin{array}{l}S V D \\
(n=55)\end{array}$ & $\begin{array}{l}\text { EMCS } \\
(n=55)\end{array}$ & p Value \\
\hline Gestational age (weeks) & $38(37 \cdot 0-41 \cdot 3)$ & $40(36 \cdot 0-43 \cdot 0)$ & $40(36 \cdot 0-43 \cdot 0)$ & $\begin{array}{l}\text { ELCS } v \text { SVD: } \mathrm{p}<0.01 \\
\text { ELCS } v \text { EMCS: } \mathrm{p}<0.001 \\
\text { SVD } v \text { EMCS: } \mathrm{p}<0.05\end{array}$ \\
\hline $\begin{array}{l}\text { Birth weight (g) } \\
\text { Length of labour (hours) } \\
\text { Umbilical cord blood arterial pH }\end{array}$ & $\begin{array}{l}3320(2460-4160) \\
\overline{7} \cdot 26(7 \cdot 08-7 \cdot 37)\end{array}$ & $\begin{array}{l}3400(2100-4700) \\
6 \cdot 0(1 \cdot 0-15 \cdot 0) \\
7 \cdot 26(7 \cdot 00-7 \cdot 38)\end{array}$ & $\begin{array}{l}3410(1980-5160) \\
6 \cdot 0(0 \cdot 1-17 \cdot 0) \\
7 \cdot 22(6 \cdot 91-7 \cdot 40)\end{array}$ & $\begin{array}{l}\text { No significant difference } \\
\text { No significant difference } \\
\text { ELCS } v \text { EMCS: } \mathrm{p}<0.001\end{array}$ \\
\hline Erythroblast count $\left(\times 10^{9} / 1\right)$ & $0.30(0.00-0.49)$ & $0 \cdot 75(0 \cdot 00-5 \cdot 3)$ & $1 \cdot 10(0.00-15 \cdot 9)$ & $\begin{array}{l}\text { SVD } v \text { EMCS: } \mathrm{p}<0.05 \\
\text { ELCS } v \text { SVD: }<<0.05 \\
\text { ELCS } v \text { EMCS: }<<0.01 \\
\text { SVD } v \text { EMCS: } \mathrm{p}<0.05\end{array}$ \\
\hline Leucocyte count $\left(\times 10^{9} / 1\right)$ & $10 \cdot 6(6 \cdot 2-17 \cdot 7)$ & $13 \cdot 8(7 \cdot 25-48 \cdot 0)$ & $13 \cdot 5(4 \cdot 2-40 \cdot 3)$ & $\begin{array}{l}\text { ELCS } v \text { SVD: } \mathrm{p}<0.001 \\
\text { ELCS } v \text { EMCS: } \mathrm{p}<0.01\end{array}$ \\
\hline
\end{tabular}



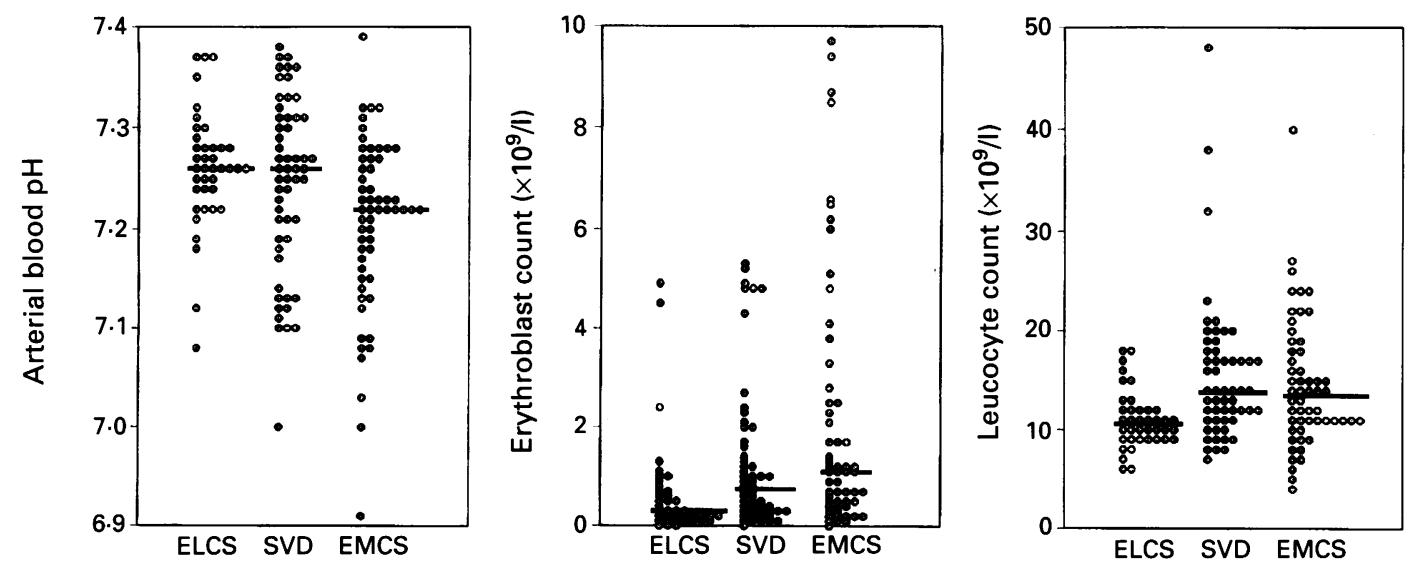

Figure 1 Umbilical cord blood arterial $p H$, erythroblast count $\left(\times 10^{9} \pi\right)$ and leucocyte count $\left(\times 10^{9} /\right)$ in the elective caesarean section (ELCS), spontaneous vaginal delivery (SVD), and emergency caesarean section (EMCS) groups.

of erythroblast and leucocyte counts towards explaining the variance in blood $\mathrm{pH}$ after correcting for the effect of labour of these variables.

\section{Results}

Gestational age, birth weight, duration of labour (time interval between the onset of painful regular uterine contractions and delivery), umbilical cord blood arterial $\mathrm{pH}$, leucocyte count, and erythroblast count in the three groups of infants are shown in the table and fig 1 . In all instances the five minute Apgar score was $\geqslant 7$. In the groups experiencing labour (spontaneous vaginal delivery and emergency caesarean section) the leucocyte and erythroblast counts were significantly higher than in the non-labour (elective caesarean section) group, but umbilical cord blood $\mathrm{pH}$ was significantly decreased only in the emergency caesarean section group (table).

In the spontaneous vaginal delivery group there were significant associations between cord blood leucocyte count and the duration of labour (fig 2: $r=0.309 ; \mathrm{p}<0.05$ ) and between

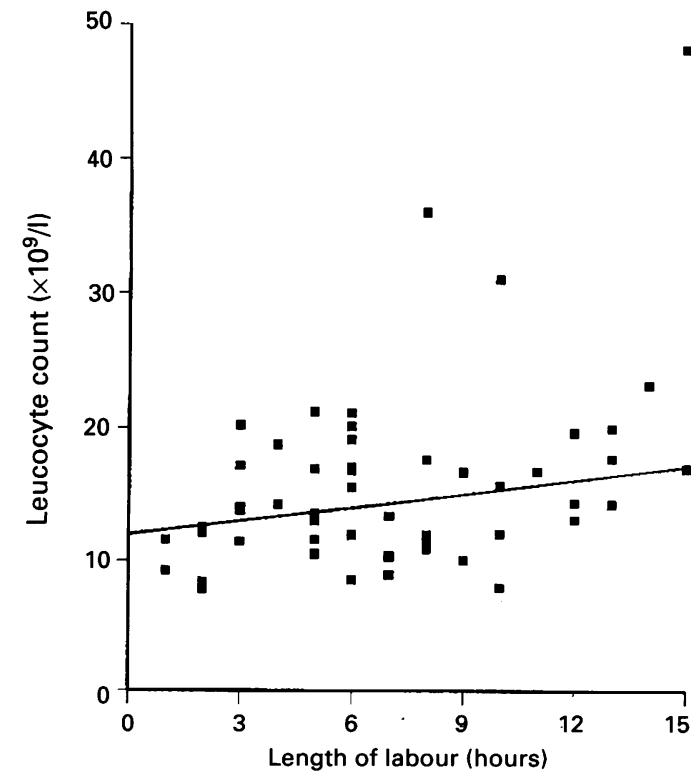

Figure 2 Relation of duration of labour with leucocyte count $\left(\times 10^{9} /\right)$ in the neonates delivered vaginally. the erythroblast count and umbilical cord blood $\mathrm{pH}$ (fig 3: $r=-0.543 ; \mathrm{p}<0.0001$ ). There was no significant association between the duration of labour and either the erythroblast count $(r=0.143)$ or umbilical cord blood $\mathrm{pH}$ $(r=-0 \cdot 229)$, or between the leucocyte count and umbilical cord blood $\mathrm{pH}(r=-0 \cdot 208)$.

In the total population umbilical cord blood $\mathrm{pH}$ was significantly associated with erythroblast $(r=-0.401 ; \mathrm{p}<0.0001)$ and leucocyte counts $(r=-0.273 ; \quad \mathrm{p}<0.001)$. Multiple regression analysis, however, showed that after correcting for the presence or absence of labour only the erythroblast count contributed significantly in explaining the variance in umbilical cord blood $\mathrm{pH}$ (erythroblast count: $r=-0.011, \mathrm{SE}=0.003, t=-3.38, \mathrm{p}<0.001$; labour: $\quad r=-0.001, \quad \mathrm{SE}=0.001, \quad t=-0.53$; leucocyte count: $r=-0.002, \quad \mathrm{SE}=0.002$, $t=-1 \cdot 32)$.

\section{Discussion}

The finding of this prospective study that labour is associated with fetal leucocytosis and erythroblastosis is compatible with previously published data. ${ }^{12}$ Although the leucocyte

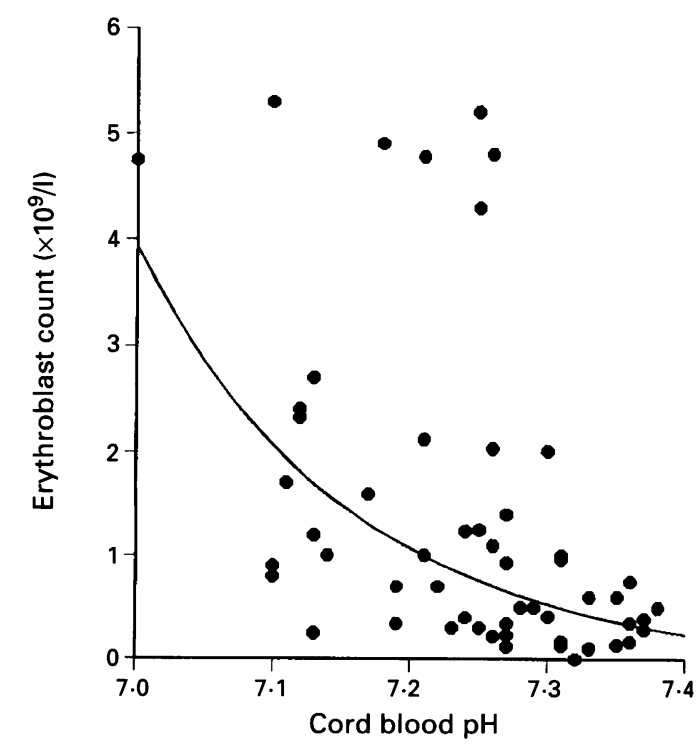

Figure 3 Relation of umbilical cord blood $\mathrm{pH}$ with erythroblast count $\left(\times 10^{9} /\right)$ in the neonates delivered vaginally. 
count was higher in the pregnancies with intrapartum fetal distress necessitating emergency caesarean section than in those delivered by elective caesarean section, there was no significant difference between the emergency caesarean section and spontaneous vaginal delivery groups. Furthermore, in the spontaneous vaginal delivery group the degree of leucocytosis was related to the length of labour but not to fetal acidaemia. These findings suggest that leucocytosis is likely to be a nonspecific response to labour.

In contrast with leucocytosis, erythroblastosis may be the consequence of fetal tissue hypoxia either before or during labour. Thus the highest erythroblast counts were observed in pregnancies complicated by intrapartum fetal distress necessitating emergency caesarean section and the magnitude of erythroblastosis was associated with the degree of fetal acidaemia.

Blood $\mathrm{pH}$ in samples obtained from the umbilical cord at delivery are susceptible to acute changes during labour and is a poor predictor of neonatal morbidity or long term handicap. 89 In contrast, plasma erythropoietin is a good measure of tissue oxygenation and increases only when physiological compensatory mechanisms such as cardiovascular responses do not prevent tissue hypoxia. ${ }^{1011}$ Furthermore, the increase in plasma erythropoietin is better correlated with erythroblast count than with $\mathrm{pH}^{4}{ }^{4}$ In this respect the degree of erythroblastosis may be a better index of hypoxic tissue damage than blood $\mathrm{pH}$. Indeed, previous retrospective studies in premature and term infants have shown that cord blood erythroblast count at delivery is a better predictor than $\mathrm{pH}$ of neonatal morbidity. ${ }^{2} 12$

The significance of the hypoxic insult to the erythroblastemic fetus remains to be established in long term neurodevelopmental studies. Furthermore, the value of erythroblast estimation as a method of intrapartum fetal monitoring, by the use of fetal scalp blood sampling, needs to be evaluated.

1 Henson VC, Block C, Eisenfield LI, et al. Effect of labour and delivery on neonatal polymorphonuclear leucocyte number and function. Am $\mathcal{f}$ Perinatol 1992; 9: 285-8.

2 Thilaganathan B, Nicolaides KH. Erythroblastosis in birth asphyxia. Ultrasound in Obstetrics and Gynecology 1992; 2: 15-7.

3 Nicolaides $\mathrm{KH}$, Thilaganathan B, Rodeck $\mathrm{CH}$, Mibashan RS. Erythroblastosis and reticulocytosis in anemic fetuses. Am f Obstet Gynecol 1988; 159: 1063-5.

4 Thilaganathan B, Salvesen DR, Abbas A, Ireland RM, Nicolaides KH. Fetal plasma erythropoietin concentration in red blood cell isoimmunized pregnancies. $A m \mathcal{F}$ tion in red blood cell isoimmunized

5 Snijders RJM, Abbas A, Melybe O, Ireland RM, Nicolaides $\mathrm{KH}$. Fetal plasma erythropoietin concentration in severe growth retardation. Am $\mathcal{f}$ Obstet Gynecol 1993; 168: $615-9$.

6 Davies NP, Snijders RJM, Nicolaides KH. Intrauterine starvation and fetal leucocyte count. Fetal Diagn Ther 1991; 6: 107-12.

7 Davies NP, Buggins AGS, Snijders RJM, Noble PN, Layton DM, Nicolaides KH. Fetal leucocyte count in rhesus disease. Arch Dis Child 1992; 67: 404-6.

8 Low JA. The role of blood gas and acid-base assessment in the diagnosis of intrapartum fetal asphyxia. Am $\mathcal{F}$ Obstet Gynecol 1988; 159: 1235-40.

9 Dennis J, Johnson A, Mutch L, Yudkin P, Johnson P. Acid base status at birth and neurodevelopmental outcome at four and a half years. Am $\mathcal{F}$ Obstet Gynecol 1989; 161: 213-20.

0 Fisher JW. Control of erythropoietin production. Proc Soc Exp Biol Med 1983; 173: 289-305.

11 Krantz SB. Erythropoietin. Blood 1991; 77: 419-34.

12 Philip AGS, Tito AM. Increased nucleated red blood cell counts in small for gestational age infants with very low birth weights. Am $\mathcal{F}$ Dis Child 1989; 143: 164-9. 